\title{
A Beleza e Estética: Razão Áurea ou Número Plástico?
}

\author{
Marcela Arantes Magri \\ Colégio Agostiniano São José \\ São José do Rio Preto, SP \\ E-mail: marantesmagri@gmail.com \\ José Antonio Salvador \\ Universidade Federal de São Carlos - Departamento de Matemática \\ Rod. Washington Luís, Km 235 - C.P. 676 \\ 13565-905 São Carlos, SP - Brasil \\ E-mail: salvador@dm.ufscar.br
}

\begin{abstract}
RESUMO
Os enormes desafios para melhorar o ensino básico de matemática nas escolas passam pela desvalorização geral e as precárias condições dos professores, pela situação de estudantes passivos neste mundo com excesso de informação, desmotivados e que nem sempre enxergam a beleza e a importância do aprendizado matemático. Visando a busca de um ambiente interativo de aprendizagem com cenários sociais importantes para o desenvolvimento cognitivo em que a mediação do professor orientador leva os estudantes a participar, pensar, planejar, estabelecer relações, comparar, criticar, imaginar e conjecturar para ampliar sua capacidade cognitiva e sócio-afetiva nos levou a questionar e sugerir algumas abordagens diferentes com a modelagem matemática e interdisciplinaridade.

Buscamos problemas ligados a arte, estética e biometria para motivação do estudante e exploração de conteúdos matemáticos em vários níveis de ensino. De fato, o apelo para os padrões de beleza tem aumentado consideravelmente devido a mídia e a busca pelas proporções tão faladas das obras de arte, da natureza e do corpo humano, como a procura pelo sorriso perfeito, dentre as várias possibilidades de exploração são as que centraremos nossa atenção neste trabalho, ampliando o espaço escolar e visando a atuação crítica do estudante. Com isso, o professor pode despertá-lo para o aprendizado significativo especialmente abordando os conceitos simples que vão desde razões e proporções, funções lineares e afim, equações de segundo grau, gráficos, raízes, equações discretas, média, ajustes, etc. que a princípio, poderiam não ter significados reais para o estudante.

O questionamento dos modelos quando eles são considerados prontos e aceitos sem discussão, verificação e comprovação podem se originar através do estudo de obras de arte e de partes do corpo humano.

Concluímos que a apresentação e abordagem de modelos matemáticos interdisciplinares explorando os padrões considerados de beleza e estética, utilizando a pesquisa de obras de arte e biométricas pode motivar, ampliar a postura crítica, o conhecimento do estudante, contemplar o ato educativo e propiciar a transformação da sala de aula.

Referências geométricas são fundamentais na nossa vida cotidiana e as razões como $1 / 2$, $1 / 3,3 / 4, \sqrt{2}$, razão áurea $\sim 1.618$, número plástico $\sim 1.32$ etc. bem como elementos proporcionais são utilizados pelo homem desde os tempos mais remotos nas relações entre medidas de objetos etc.
\end{abstract}


Propomos a exploração das razões das medidas das pinturas famosas desde artistas renascentistas até modernistas, e se pode verificar que realmente a razão áurea não é a que mais aparece na relação entre o tamanho das obras de arte conforme os trabalhos de MARKOWSKY, 1992 e de OLARIU, 2008. Mostramos que o valor mais próximo é o número plástico (ou de Padovan). Consideramos também, várias fotos de sorrisos considerados estéticos e ajustamos os dados das medidas dos incisivos centrais e incisivos laterais mostrando que a razão áurea sim, aparece aí. Neste caso, o cirurgião dentista pode utilizar uma relação entre a largura do sorriso LS e a largura do incisivo central LIC dada por LIC $=0,155 \mathrm{LS}$, e assim,planejar a prótese do incisivo central de seu paciente e em seguida com o tamanho ideal do incisivo central calculado em função da largura do sorriso, utiliza a razão áurea entre a largura do incisivo central LIC e a largura do incisivo lateral LIL: 1,618 LIL = LIC para providenciar o tamanho da prótese do incisivo lateral do paciente. Ela aparece em partes das de algumas pinturas e em outras situações como em problemas de detecção e reconhecimento e recuperação facial. Entretanto, nem todas as belas obras de arte que admiramos estão na razão áurea e isto pode ser bastante explorado e criticado pelos estudantes.

\section{Referências}

[1] R. C. Bassanezzi, "Ensino-aprendizagem com modelagem matemática”, Ed. Contexto, São Paulo, 2002.

[2] A.C. Francischone ,J. Mondelli,A ciência da beleza do sorriso. Revista dentpress estética, p. 97-106(2007).

[3] A. C. Francischone, "Prevalência das proporções áurea e estética dos dentes ânterosuperiores e respectivos segmentos dentários relacionadas com a largura do sorriso em indivíduos com oclusão normal”. Dissertação de mestrado - Faculdade de Odontologia de Bauru, Universidade de São Paulo, 2005.

[4] G. Markowsky, Misconceptions about the Golden Ratio.Mathematical Association of America,vol. 23, pp. 2-19, (1992).

[5] J. Mondelli. "Estética e cosmética em clínica integrada restauradora”. São Paulo: Ed. Santos, 2003 